\title{
Pneumonitis in Irradiated Lungs After Nivolumab: A Brief Communication and Review of the Literature
}

\author{
Farkhad Manapov, ${ }^{+}$Olarn Roengvoraphoj, ${ }^{*}$ Maurice Dantes, ${ }^{*}$ \\ Sebastian Marschner,* Minglun Li, and Chukwuka Eze*
}

\begin{abstract}
Summary: Nivolumab is a feasible therapy option in patients with advanced non-small cell lung cancer (NSCLC) who progress on first-line treatment. However, there is limited information about an overlapping toxicity of PD-1 inhibitors when administered following thoracic radiotherapy (TRT). Three of 25 patients with advanced NSCLC were treated with palliative or curative intent. Nivolumab was initiated as second or third-line therapy after TRT for recurrent or progressive disease. All 3 patients developed grade 3 pneumonitis at some point during nivolumab therapy. Herein, we describe 3 cases of pneumonitis in patients with NSCLC started on nivolumab following TRT. Imaging analysis was strongly consistent with heterogenous lung parenchyma changes in the irradiated lung volume receiving a total dose of 15-20 Gy. Pulmonary toxicity was manageable; however, interruption of immunotherapy was necessary.
\end{abstract}

Key Words: immunotherapy, nivolumab, non-small cell lung cancer, radiation recall pneumonitis, thoracic radiotherapy

(J Immunother 2018;41:96-99)

$\mathrm{N}$ ivolumab is an effective, feasible treatment option in advanced non-small cell lung cancer (NSCLC). On the basis of CheckMate $017^{1}$ and CheckMate $057,{ }^{2}$ nivolumab was approved as second-line standard, unrestricted for use independent of PD-L1 status.

Because of potential overlapping pulmonary toxicity, a combination of immunotherapy and thoracic radiotherapy (TRT) is an important point of clinical investigation. A meta-analysis on the risk of pneumonitis associated with immunotherapy reported a relatively low incidence of allgrade $(2.9 \%)$ and high-grade $(1.8 \%)$ pulmonary toxicity, respectively. The incidence of pneumonitis was higher in nonmelanoma patients. ${ }^{3}$ However, a phase I dose-escalation cohort expansion trial (CA209-003) of nivolumab documented higher pneumonitis rates in 129 NSCLC patients with previous TRT. There were $7 \%$ and $1.3 \%$ of all-grade and grade 3-4 pneumonitis, respectively.,5 Herein, we describe 3 cases of severe pneumonitis in irradiated lungs of pretreated NSCLC patients on nivolumab.

Received for publication July 25, 2017; accepted October 22, 2017.

From the *Department of Radiation Oncology, University Hospital, LMU Munich; and †Comprehensive Pneumology Center Munich (CPC-M), Munich, Germany.

F.M. and O.R. contributed equally to this work.

Presented in part at the seventh edition of the European Lung Cancer Conference 2017 (ELCC 2017), which took place from May 5 to 8, 2017, in Geneva, Switzerland.

Reprints: Chukwuka Eze, Department of Radiation Oncology, University Hospital, LMU Munich, Marchioninistrasse 15, Munich 81377, Germany (e-mail: chukwuka.eze@med.uni-muenchen.de).

Copyright (C) 2017 Wolters Kluwer Health, Inc. All rights reserved.

\section{CASE 1}

A 66-year-old female patient (exsmoker) with performance status (PS) Eastern Cooperative Oncology Group (ECOG) 1 was diagnosed with squamous NSCLC cT3cN2cM0 (UICC seventh edition). Radical surgery was performed after 4 cycles of neoadjuvant cisplatin/vinorelbine. Four weeks later, postoperative radiotherapy was delivered to a total dose of $50.0 \mathrm{~Gy}$. The lung dose-volume histogram parameters were as follows: V20 (both lungs) $16 \%(519 \mathrm{~mL})$, mean lung dose (MLD) 11.85 Gy (Fig. 1A2). On recurrence, the patient was started on nivolumab. Shortly after the first cycle, she developed grade 3 dyspnea. High-resolution chest computed tomography (CT) showed a patchy consolidation (Fig. 1A4). No pathologic findings were observed on bronchoscopy. Broncho-alveolar lavage (BAL) showed 60.6\% macrophages, 9.3\% lymphocytes, and 30\% neutrophils. Microbiological analysis of BAL was negative. Corresponding changes in pulmonary function tests (PFTs) before and after the onset of pneumonitis are shown in Table 1. Immunotherapy was interrupted and the patient was started on corticosteroids tapered slowly over 5 weeks.

\section{CASE 2}

A 76-year-old male patient (nonsmoker) with PS ECOG 1 presented with oligometastatic NSCLC cT1cN2cM1b (UICC seventh edition) and received stereotactic radiosurgery for 2 brain lesions. Thereafter, 2 cycles of chemotherapy with cisplatin/pemetrexed followed. PET/CT showed partial remission (Fig. 1B1), concurrent chemoradiotherapy with cisplatin/pemetrexed to a total dose of $66.0 \mathrm{~Gy}$ was delivered. The lung dose-volume histogram parameters were as follows: V20 (both lungs) $22 \%(930 \mathrm{~mL})$ and MLD $12.3 \mathrm{~Gy}$, respectively (Fig. 1B2). Four months later, the patient presented with metastatic disease and was started on nivolumab. Shortly after the fourth application, he developed grade 3 dyspnea requiring immediate hospitalization, chest CT showed irregular ground-glass opacities with bilateral fibrotic changes (Fig. 1B4), BAL showed 9.6\% macrophages, 5.6\% lymphocytes, $84.6 \%$ neutrophils. Microbiological analysis of BAL was negative. The corresponding changes in PFTs before and after the onset of pneumonitis are illustrated in Table 1. Immunotherapy was interrupted and the patient was started on $50 \mathrm{mg}$ prednisolone tapered off $5 \mathrm{mg}$ every 4 days over 6 weeks.

\section{CASE 3}

A 56-year-old female patient (nonsmoker) with PS ECOG 1 was diagnosed with stage IV NSCLC with multiple brain metastases. She was initially treated with 5 cycles of cisplatin/pemetrexed and responded well, exhibiting partial remission. Three weeks later, she underwent palliative irradiation to the brain and thorax. V20 (both lungs) and MLD were $18 \%(380 \mathrm{~mL})$ and $9.45 \mathrm{~Gy}$, respectively (Fig. 1C2). Three months later, docetaxel/nintedanib was initiated due to progressive disease; however, the patient developed adrenal metastasis and was started on nivolumab. Restaging scans after 6 cycles revealed diffuse consolidations in both upper lobes (Fig. 1C4). The patient presented with grade 3 dyspnea also requiring immediate hospitalization. BAL revealed bronchial epithelial cells with macrophages and neutrophils. Microbiological analysis of BAL was negative. For changes in the PFTs see Table 1. Nivolumab was interrupted and treatment with $60 \mathrm{mg}$ prednisolone was started, tapered off $5 \mathrm{mg}$ every 4 days for 6 weeks. 


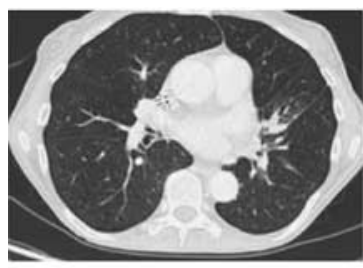

A1: CT scan before radiation

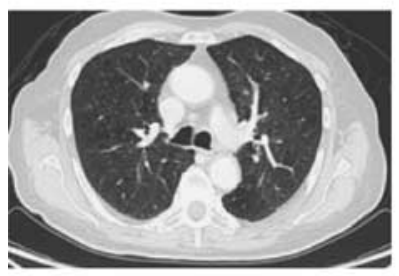

B1: CT scan before radiation

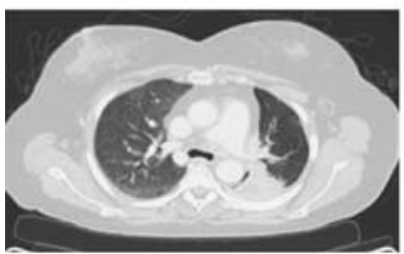

$\mathrm{C} 1$ : CT scan before radiation

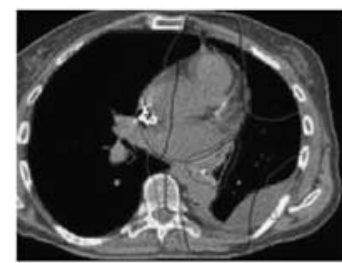

A2: Radiation treatment plan (Green V15, Purple V20 area)

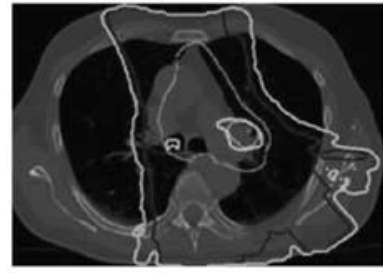

B2: Radiation treatment plan (green V15, blue V20 area)

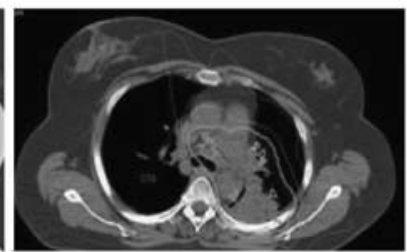

C2: Radiation treatment plan (blue V20 area)

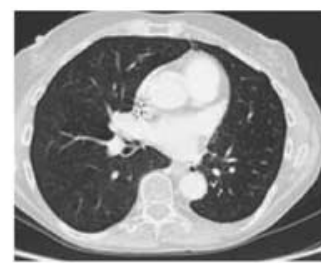

A3: 3 months after radiation

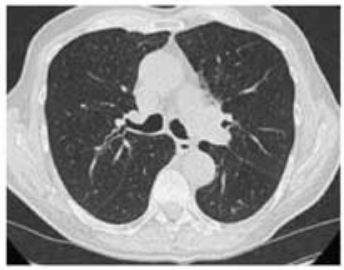

B3: 7 weeks after radiation

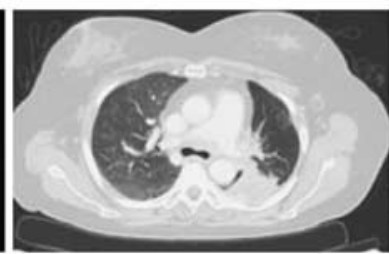

C3: 2 months after radiation

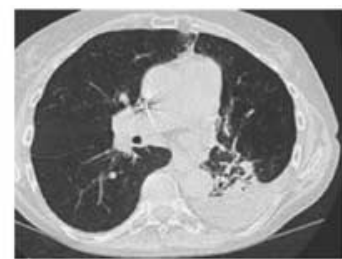

A4: 5 months after radiation, during Nivolumab treatment

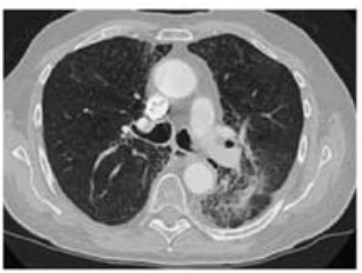

B4: 5 months after radiation, during Nivolumab treatment

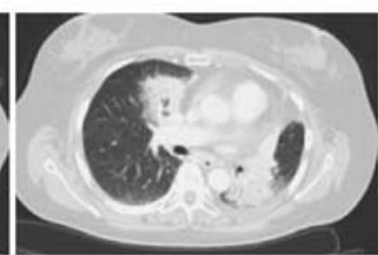

C4: 10 months after radiation, during Nivolumab treatment

FIGURE 1. A-C, Diagnostic, radiotherapy and follow-up computed tomography (CT) imaging.

\section{DISCUSSION}

On the basis of several randomized trials, monotherapy with nivolumab is becoming an established standard in NSCLC patients who progress on/after first-line treatment. 1,2 Phase II and III trials investigating the feasibility of nivolumab concomitantly or as consolidation after chemoradiotherapy in stage III NSCLC are underway (NICOLAS-ETOP ${ }^{6}$ RTOG 3505 ).

Importantly, the potential overlapping of pulmonary toxicity of nivolumab and TRT is still unclear. The latest review on this issue cited only 2 case reports. Moreover, a recently published piece by Shibaki et $\mathrm{al}^{7}$ described a similar phenomenon of radiation recall pneumonitis in 2 patients previously treated with TRT 2 years before immunotherapy. Because of paucity of data in this scenario, final conclusions cannot be drawn. ${ }^{8}$ The majority of studies on combined immunoradiotherapy referred to patients with melanoma treated with intracranial stereotactic radiosurgery. ${ }^{9,10} \mathrm{Lu}$ and $\mathrm{Liu}^{11}$ recently reported on 3 cases of pneumonitis in patients with melanoma, thymoma,

\begin{tabular}{|c|c|c|c|c|}
\hline PFT & Pretreatment PFT & 1 mo After TRT & 5 mo After TRT & \\
\hline \multirow[t]{2}{*}{ Case 1} & $\begin{array}{c}\text { VC max: } 3.14(120.2 \%) \\
\text { FEV1: } 1.64(78.1 \%) \\
\text { DLCO SB: } 2.38(33.3 \%) \\
\text { DLCO/VA: } 0.56(37 \%)\end{array}$ & $\begin{array}{c}\text { VC max: } 3.28(125.5 \%) \\
\text { FEV1: } 1.77(84.3 \%) \\
\text { DLCO SB: } 2.91(40.6 \%) \\
\text { DLCO/VA: } 0.62(41.3 \%)\end{array}$ & $\begin{array}{c}\text { VC max: } 2.56(98.8 \%) \\
\text { FEV1: } 1.46(70.7 \%) \\
\text { DLCO SB: } 1.93(27.1 \%) \\
\text { DLCO/VA: } 0.53(35.6 \%)\end{array}$ & \\
\hline & Pretreatment PFT & 2 mo after TRT & $7 \mathrm{mo}$ after TRT & $8 \mathrm{mo}$ after TRT \\
\hline \multirow[t]{2}{*}{ Case 2} & $\begin{array}{c}\text { VC max: } 4.73(111.8 \%) \\
\text { FEV1: } 2.80(91 \%) \\
\text { DLCO SB: } 5.06(56.1 \%) \\
\text { DLCO/VA: } 0.87(70.8 \%)\end{array}$ & $\begin{array}{c}\text { VC max: } 4.13(97.7 \%) \\
\text { FEV1: } 2.49(81.1 \%) \\
\text { DLCO SB: } 3.13(34.7 \%) \\
\text { DLCO/VA: } 0.56(45 \%)\end{array}$ & $\begin{array}{c}\text { VC max: } 3.31(78.7 \%) \\
\text { FEV1: } 2.57(84.5 \%) \\
\text { DLCO SB: } 1.85(20.7 \%) \\
\text { DLCO/VA: } 0.41(33.2 \%)\end{array}$ & $\begin{array}{c}\text { VC max: } 4.03(95.9 \%) \\
\text { FEV1: } 2.72(89.2 \%) \\
\text { DLCO SB: } 2.69(30 \%) \\
\text { DLCO/VA: } 0.48(39.3 \%)\end{array}$ \\
\hline & Pretreatment PFT & 2 mo after TRT & $11 \mathrm{mo}$ after TRT & $14 \mathrm{mo}$ after TRT \\
\hline Case 3 & $\begin{array}{c}\text { VC max: } 2.99(92.57 \%) \\
\text { FEV1: } 2.21(83.1 \%) \\
\text { DLCO SB: } 3.58(43.08 \%) \\
\text { DLCO/VA: NA }\end{array}$ & $\begin{array}{c}\text { VC max: } 3.05(94.43 \%) \\
\text { FEV1:2.27 }(85.34 \%) \\
\text { DLCO SB: } 3.64(43.8 \%) \\
\text { DLCO/VA: NA }\end{array}$ & $\begin{array}{c}\text { VC max: } 2.24(70 \%) \\
\text { FEV1: } 1.72(65.15 \%) \\
\text { DLCO SB: } 2.88(34.87 \%) \\
\text { DLCO/VA: NA }\end{array}$ & $\begin{array}{c}\text { VC max: } 2.31(72.2 \%) \\
\text { FEV1: } 1.70(64.4 \%) \\
\text { DLCO SB: } 2.67(32.32 \%) \\
\text { DLCO/VA: NA }\end{array}$ \\
\hline
\end{tabular}

DLCO indicates diffusion capacity of the lungs for carbon monoxide; NA, not available; PFT, pulmonary function test; SB, single breath; TRT, thoracic radiotherapy; VA, alveolar volume; VC, vital capacity. 


\begin{tabular}{|c|c|c|c|c|c|c|c|c|}
\hline References & $\begin{array}{l}\text { Patient } \\
\text { No. }\end{array}$ & $\begin{array}{l}\text { Study } \\
\text { Design }\end{array}$ & $\begin{array}{l}\text { Tumor } \\
\text { Type }\end{array}$ & Stage & TRT & Immunotherapy & $\begin{array}{c}\text { Concurrent } \\
\text { vs. Sequential }\end{array}$ & Pneumonitis Rate \\
\hline $\mathrm{Lu}$ and $\mathrm{Liu}^{11}$ & 3 & $\begin{array}{l}\text { Case } \\
\text { report }\end{array}$ & $\begin{array}{l}\text { Pulmonary } \\
\text { metastasis }\end{array}$ & IV & Yes & $\begin{array}{l}\text { Pembrolizumab } \\
\text { and Nivolumab }\end{array}$ & Sequential & All patients after 4 cycles \\
\hline Miyoshi et al ${ }^{15}$ & 1 & $\begin{array}{l}\text { Case } \\
\text { report }\end{array}$ & NSCLC & IIIB & Yes & Nivolumab & Sequential & $\begin{array}{l}\text { Patient developed Pneumonitis } \\
\text { after } 3 \text { cycles }\end{array}$ \\
\hline $\begin{array}{l}\text { Khunger } \\
\text { et } \mathrm{al}^{13}\end{array}$ & 5038 & $\begin{array}{l}\text { Meta- } \\
\text { analysis }\end{array}$ & NSCLC & - & Yes & $\begin{array}{l}\text { PD-1 and PD-L1 } \\
\text { inhibitors }\end{array}$ & Sequential & $\begin{array}{l}\text { The incidence of any grade pneumonitis } \\
\text { was significantly higher with PD-1 } \\
\text { inhibitors than with PD-L1 inhibitors } \\
(3.6 \%, 95 \% \text { CI, } 2.4 \%-4.9 \% \text { vs. } 1.3 \% \text {, } \\
95 \% \text { CI } 0.8 \%-1.9 \%) \\
\text { Grade } 5 \text { pneumonitis in } 7,3 \text { of these } \\
\text { patients treated with radiation }\end{array}$ \\
\hline CA $209-003^{4,5}$ & 129 & Phase I & NSLCC & - & Yes & Nivolumab & Sequential & $\begin{array}{l}7 \% \text { for all-grade pneumonitis } \\
1.3 \% \text { for grade } 3-4 \text { pneumonitis }\end{array}$ \\
\hline Shibaki et $\mathrm{al}^{7}$ & 2 & $\begin{array}{l}\text { Case } \\
\text { report }\end{array}$ & NSCLC & - & Yes & Nivolumab & Sequential & Both patients \\
\hline $\begin{array}{l}\text { Durm et al } \\
(2017)^{12}\end{array}$ & $\begin{array}{c}83 / 93 \\
\text { evaluable }\end{array}$ & $\begin{array}{l}\text { Phase } \\
\text { II }\end{array}$ & NSCLC & III & Yes & Pembrolizumab & Sequential & $\begin{array}{l}20.5 \% \text { any grade pneumonitis } \\
3.6 \% \text { grade } 3-5 \text { pneumonitis }\end{array}$ \\
\hline
\end{tabular}

and jejunal adenocarcinoma treated with PD-1 inhibitors and radiotherapy.

Previous results, including a meta-analysis detected a very low incidence of immune-related pneumonitis in patients treated with PD-1 inhibitors. ${ }^{1-3}$ In contrast, a phase I dose-escalation cohort expansion trial (CA209-003) of nivolumab including 129 NSCLC patients pretreated with TRT revealed a 7\% incidence of all grade pneumonitis. ${ }^{4,5}$ In addition, a recent phase II study presented at ASCO 2016 showed an incidence of $20.5 \%$ for all grade and 3.6\% for grade 3-5 pneumonitis in patients treated with consolidation pembrolizumab initiated 1-2 months following concurrent chemoradiotherapy. ${ }^{12}$

Furthermore, in a recent meta-analysis, grade 5 pneumonitis was described in seven patients treated with PD-1 inhibitors. Three of these patients were treated with thoracic radiotherapy before PD-1 inhibitors. ${ }^{13}$ On the basis of this data, a higher risk for immune-related pulmonary toxicity in this patient cohort can be supposed.

Herein, we presented a case study with grade 3 pneumonitis in the irradiated lungs of pretreated NSCLC patients undergoing immunotherapy. In all cases, extensive imaging and bronchoscopy were performed on onset of respiratory symptoms. Nivolumab was interrupted and all patients were started on corticosteroids for the following 5 to 6 weeks with relatively rash alleviation of symptoms. Median time from the end of TRT to manifestation of pneumonitis was 167 days indicating an importance of careful follow-up for early signs and symptoms of pneumonitis throughout successive treatment with immune-checkpoint inhibitors. Extensive imaging analysis was strongly consistent with broadly based parenchyma changes in the irradiated lung volume receiving 15-20 Gy. A relatively low MLD and the timing of the onset of pneumonitis in all 3 cases, makes a case against sole radiation-induced lung injury (RILI). ${ }^{14}$ However, a synergistic effect of TRT on immune-related pneumonitis or counterpart nivolumab effect on the induction of RILI could not be excluded.

Clinical and fundamental research of pneumonitis and RILI is urgently required. Despite the ever-increasing continuous application of immunotherapy prior and following TRT in patients with advanced lung cancer, there has not been much progress in the investigation of immunological aspects of immunotherapy-induced and radiation-induced lung injury. Our case study underscores the importance of this problem. Table 2 displays a summary of the current evidence on the incidence of pneumonitis in various reports and studies.

In conclusion, in our current study all 3 patients achieved a durable response; however, this was at the cost of severe pulmonary toxicity, which was manageable in all cases. A detailed analysis of the described overlapping toxicity in pretreated NSCLC patients will be performed within the scope of a planned single-center prospective trial.

\section{CONFLICTS OF INTEREST/ FINANCIAL DISCLOSURES}

None reported. All authors have declared that there are no financial conflicts of interest with regard to this work.

\section{REFERENCES}

1. Brahmer J, Reckamp KL, Baas P, et al. Nivolumab versus docetaxel in advanced squamous-cell non-small-cell lung cancer. N Engl J Med. 2015;373:123-135.

2. Borghaei H, Paz-Ares L, Horn L, et al. Nivolumab versus docetaxel in advanced nonsquamous non-small-cell lung cancer. N Engl J Med. 2015;373:1627-1639.

3. Peng L, Zhao Q, Ye X, et al. Incidence and risk of pneumonitis associated with nivolumab and pembrolizumab in patients with cancer: A meta-analysis of clinical trials. J Clin Oncol. 2016;34 (suppl):e21651

4. Topalian SL, Sznol M, McDermott DF, et al. Survival, durable tumor remission, and long-term safety in patients with advanced melanoma receiving nivolumab. J Clin Oncol. 2014; 32:1020-1030.

5. Topalian SL, Hodi FS, Brahmer JR, et al. Safety, activity, and immune correlates of anti-PD-1 antibody in cancer. $N$ Engl $J$ Med. 2012;366:2443-2454.

6. Peters S, Stahel RA, Kassapian M, et al. 80TiPA feasibility trial evaluating the addition of nivolumab to standard first-line chemo-radiotherapy in locally advanced stage IIIA/B NSCLC: The ETOP 6-14 NICOLAS trial. Ann Oncol. 2017;28 (suppl_2). Doi:10.1093/annonc/mdx092.009. 
7. Shibaki R, Akamatsu H, Fujimoto $M$, et al. Nivolumab induced radiation recall pneumonitis after two years of radiotherapy. Ann Oncol. 2017;28:1404-1405.

8. Kroeze SGC, Fritz C, Hoyer M, et al. Toxicity of concurrent stereotactic radiotherapy and targeted therapy or immunotherapy: a systematic review. Cancer Treat Rev. 2017;53:25-37.

9. Liniker E, Menzies AM, Kong BY, et al. Activity and safety of radiotherapy with anti-PD-1 drug therapy in patients with metastatic melanoma. Oncoimmunology. 2016;5:e1214788.

10. Ribeiro Gomes J, Schmerling RA, Haddad CK, et al. Analysis of the Abscopal Effect with anti-PD1 therapy in patients with metastatic solid tumors. J Immunother. 2016;39:367-372.

11. $\mathrm{Lu} \mathrm{C-S,} \mathrm{Liu} \mathrm{J-H.} \mathrm{Pneumonitis} \mathrm{in} \mathrm{cancer} \mathrm{patients} \mathrm{receiving}$ anti-PD-1 and radiotherapies: three case reports. Medicine (Baltimore). 2017;96:e5747.
12. Durm GA, Kio EA, Fisher WB. Phase II trial of consolidation pembrolizumab following concurrent chemoradiation in patients (pts) with unresectable or inoperable stage III non-small cell lung cancer (NSCLC): Initial safety data from HCRN LUN 14-179. Clin Oncol. 2016.

13. Khunger $M$, Rakshit $S$, Pasupuleti $V$, et al. Incidence of pneumonitis with use of PD-1 and PD-L1 inhibitors in non-small cell lung cancer. Chest. 2017;152:271-281.

14. Kwa SL, Lebesque JV, Theuws JC, et al. Radiation pneumonitis as a function of mean lung dose: an analysis of pooled data of 540 patients. Int J Radiat Oncol Biol Phys. 1998;42:1-9.

15. Miyoshi K, Fujisaka Y, Nakamura T, et al. A first report of nivolumab induced radiation recall pneumonitis (Abstract) ESMO Asia 2016 Congress, 2016. 